\title{
LA MURALLA MEDIEVAL DE ELCHE
}

\author{
José Hinojosa Montalvo
}

\section{RESUMEN}

La muralla en Elche va a desempeñar un papel defensivo fundamental, a la vez que marca la separación entre la villa y el campo. Desde el punto de vista político, las murallas pertenecen al común de los ciudadanos, y es el municipio el encargado de su buen mantenimiento. Esa muralla era administrada por el Consell, a través de un obrer de murs. Hay un importante componente social en torno al muro, que va desde la celebración del mercado a juegos y deportes.

\begin{abstract}
The wall around Elche played an important role in defense of the village and also served to separate the town itself from the surrounding countryside. From a political perspective, the wall was held in common countryside. From a political perspective, the wall was held in common proprietorship and the municipality was responsible for its care and maintenance. The wall was controlled by the Town Council which employed a caretaker. The area around the wall served as an important social gathering point and a variety of activities including markets, games and sporting took place there.
\end{abstract}

Al sur de la actual provincia de Alicante, surcada por el río Vinalopó que le da nombre, se encuentra la comarca del Bajo Vinalopó, cuya capital ha sido y sigue siendo Elche. La comarca tiene una unidad histórica, pero también fisiográfica, al configurarse como un amplio glacis cuaternario entre las sierras de Crevillente, Negra, Alt del Muro, Tabaià, Grossa, Sancho y Colmenares, hasta el litoral y la Albufera de Elche. En el relieve predominan los sedimentos desde el Neógeno a la actualidad, sobre los que han actuado movimientos de subsidencia y de emersión, así como la acción erosiva ${ }^{1}$.

La comarca presentaba en estos siglos una unidad basada en criterios históricos, que tenían su punto de partida en el extenso donadío entregado al infante don Manuel tras la incorporación del reino hudita de Murcia a Castilla, que comprendía también el medio

1 VERA REBOLLO, J.: «El Bajo Vinalopó», Historia de la Provincia de Alicante, tomo I, Murcia, Ediciones Mediterráneo, 1985, pp. 315-370. 
Vinalopó y otras plazas. La villa de Elche, poblada de cristianos y con un arrabal mudéjar, y el lugar de Crevillente, de moros, eran las dos únicas localidades de la comarca, ya que en el litoral donde más tarde surgirá Santa Pola tan sólo se constata la existencia de la torre del Cap del Aljup ${ }^{2}$. La superior categoría poblacional de Elche sobre la vecina Crevillente se aprecia en la categoría de «vila», de que disfrutaba, frente a Crevillente, que sólo fue un «lloc». Desde fines del siglo XIV mantuvieron unidos sus destinos al ser compradas por Barcelona y pasar a formar parte de su señorío. La creación posterior del marquesado de Elche mantuvo la unidad histórica del territorio.

Así pues, a lo largo de la Historia, Elche se ha configurado como la cabeza de los núcleos urbanos de la comarca. Pero el emplazamiento de la ciudad no fue siempre el mismo, ya que la Ilici romana se asentaba en l'Alcudia, a unos dos $\mathrm{Km}$. de distancia. La decadencia de la ciudad acabó originando su cambio de emplazamiento en época musulmana, buscando mejores condiciones de defensa y de utilización del agua, así como un mejor aprovechamiento para la agricultura, huyendo de los accidentes montañosos del norte y de la zona pantanosa de la Albufera y alrededores. Sin olvidar, claro está, la buena situación de Elche en relación con la ruta Alicante-Orihuela-Murcia, y la que por el valle del Vinalopó conducía hacia la Mancha.

Elche se configura como una ciudad de llanura, en cuyo trazado puede percibirse la influencia de la infraestructura creada por el catastro romano. Se aprecia un parcelario ortogonal, fosilizado por la red de acequias y caminos, que posteriormente fue respetado en el viario de la Vila murada y del Raval ${ }^{3}$.

Nos encontramos con un hábitat condicionado por la geografía, en un terreno llano, sin más posibilidades de defensa natural que el cauce del Vinalopó. Pero que también se verá condicionado por el momento histórico de la Edad Media, derivado de la existencia de la frontera. Elche, igual que Alicante y Orihuela, fue considerado durante estos siglos como tierra de frontera, es decir zona de riesgo, de peligro militar. Primero, mientras perteneció a la Corona de Castilla, como frontera frente a Aragón. Luego, cuando a principios del siglo XIV se incorpora al reino de Valencia, frontera hacia el Sur, hacia el vecino reino de Murcia. Y en todo momento frontera con el Islam, con los nazaríes del reino de Granada o con los piratas norteafricanos o granadinos, cuyos ataques se dejaron sentir con regularidad sobre el despoblado litoral ilicitano, con sus secuelas de cautivos ${ }^{4}$. Mucho más peligrosas fueron las incursiones granadinas, que penetraban con facilidad atravesando el despoblado reino de Murcia y contando al menudo con la connivencia de los mudéjares valencianos. Baste recordar el famoso ataque del caudillo granadino Ridwan en 1332, que asedió Elche, aunque no pudo tomarla, pero que dejó fuerte impacto en el subconsciente

Por tanto, el hecho defensivo se muestra de una importancia decisiva a la hora de justificar la existencia de una muralla, tras la cual se pueden refugiar los habitantes, tanto de la villa como del término. El poder ponerse a cubierto tras unas sólidas defensas era un factor básico en la guerra medieval, debido a la superioridad de los medios defensivos sobre los de ataque. Para Y. Barel «la ciudad, hecho militar, se inscribe en el estrecho

2 HINOJOSA MONTALVO, J.: «El Cap del Aljup, puerto medieval de Elche», Mayurga, 23, Homenaje a Álvaro Santamaría, Palma de Mallorca, 1989, I, pp. 311-324.

3 GOZÁLVEZ PÉREZ, V.: La ciudad de Elche, Universidad, Departamento de Geografía, Valencia, 1976. En concreto ver también la obra de GOZÁLVEZ PÉREZ, V.: «La centuriatio de Ilici», Estudios sobre centuriaciones romanas en España, Madrid, Universidad Autónoma, 1974, pp. 101-113. VERA, J. F.: ob. cit., p. 338.

4 HINOJOSA MONTALVO, J.: «Cristianos, mudéjares y granadinos en la Gobernación de Orihuela», $I V$ Coloquio Internacional de Historia Medieval Andaluza, Almería, 1988, pp. 323-342. FERRER MALLOL, M." T.: La frontra amb l'Islam en el segle XIV. Cristians $i$ sarraïns al País Valencià, Barcelona, 1988. 


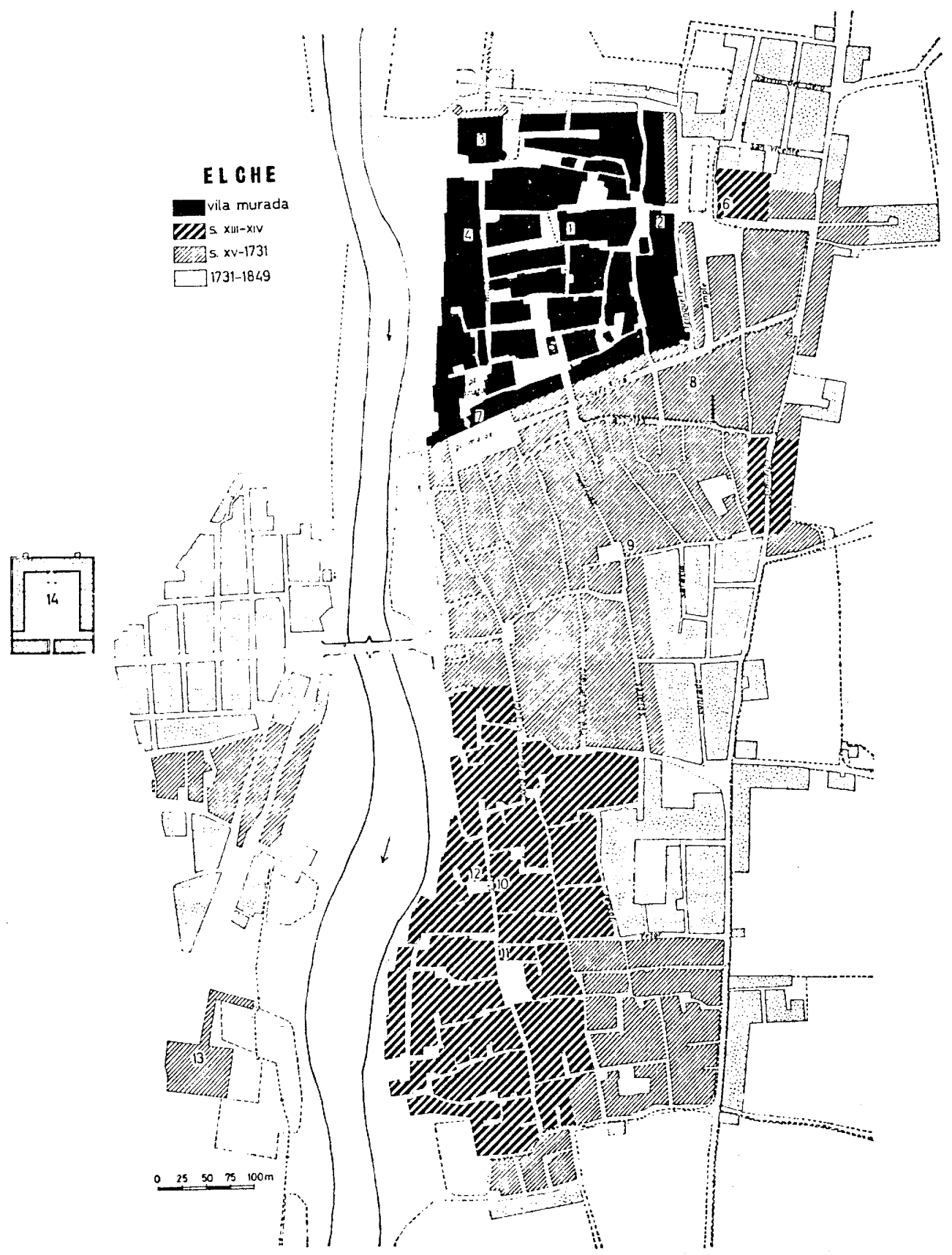

Evolución urbana hasta 1849: 1. Templo de Santa María (antigua mezquita).- 2. Fortaleza de la Calaforra, junto a la puerta del mismo nombre.-- 3. L'Alcàsser de la Senyoria.- 4. Ermita de San Sebastián.- 5. Pescadería nueva (1849). - 6. Convento de la Merced y baños musulmanes. - 7 . Ayuntamiento de la vila - - 8. Convento de religiosas de la Encarnación.- 9. Templo del Salvador.- 10. Templo de San Juan Bautista (antigua mezquita).- 11. Antiguo Ayuntamiento del Raval de Sant Joan.- 12. Antiguo Pósito.- 13. Convento franciscano de San José.- 14. Cuartel de caballería. 
márgen que separa los métodos de combate de la caballería y los de los ejércitos de la era moderna ${ }^{5}$.

La muralla marcaba un límite material entre la ciudad y el campo, entre los vecinos de la «Vila» y los que viven en el arrabal o en las alquerías dispersas por el término. Era también un hito jurídico, y los privilegios de ciudadanía y vecindad afectaban a los que vivían intramuros. En torno a la muralla hay también importantes connotaciones económicas, al permitir a las autoridades un control bastante efectivo del tránsito de mercancías (sobre todo cereales y vino), lo que permite a su vez un mejor ejercicio de la fiscalidad.

Desde el punto de vista político, las murallas pertenecen al común de los ciudadanos, y será el municipio el que se encargue de la construcción, mantenimiento y reparación de las mismas, a través de las prestaciones en trabajo de los vecinos, de compensaciones monetarias o arbitrando impuestos especiales. La muralla será el elemento decisivo que permitirá a una aglomeración urbana, como fue el caso de Elche, alcanzar la denominación de villa, frente a otros lugares de menor importancia, que no contaban con un aparato defensivo importante, como fue el caso de la vecina Crevillente.

La muralla y sus puertas sirven de marco a otros muchos acontecimientos, desde el emplazamiento de ferias y mercados, actos públicos, juegos, etc. de forma similar a lo que vemos en el resto de Europa, sin que Elche constituya una excepción en este panorama genérico. Veamos cuál fue la evolución y significado de las murallas para el Elche medieval.

\section{La muralla medieval de Elche}

La reconstrucción del recinto amurallado de Elche en los siglos medievales ha podido hacerse con bastante fidelidad gracias a los planos conservados del siglo XVIII y de 1849 , así como las descripciones que aparecen en los Manuals de Consells de los siglos XVI y XVII sobre su demolición. Una primera noticia de carácter general nos la dio en 1621 el regidor de Elche, Cristobal Sanz, a quien luego han seguido los diversos autores que han tocado el tema ${ }^{6}$. Será V. Gozálbez, quien en su libro «La ciudad de Elche» nos ofrezca la mejor síntesis de lo que fueron las murallas ilicitanas ${ }^{7}$, descripción utilizada por cuantos se interesan por el tema y es la que yo también utilizaré, tratando de contrarrestarla con la documentación de la época, superando el mero nivel descriptivo o narrativo, para tratar de ver la confluencia de funciones que convergían en ella: la militar, de protección; la de demarcación de la colectividad humana, y el reflejo del potencial político y militar de sus habitantes ${ }^{8}$.

5 BAREL, Y.: La ciudad medieval. Sistema social, sistema urbano, Madrid, 1981, p. 193.

6 SANZ, C.: Recopilación en que se da cuenta de las cosas ansi antiguas como modernas de la inclita villa de Elche, Ms. 1621. Elche, 1954, p. 111.

7 GOZÁLBEZ, V.: 1976, op. cit., pp. 24-31.

8 El tema de las fortificaciones y murallas comienza a ser objeto de interés monográfico en España. Al margen de las acotaciones específicas que sobre ello suele encontrarse en las historias locales, merecen destacarse algunos trabajos recientes, en particular el de LADERO QUESADA, M. A.: «Les fortifications urbaines en Castille aux XI-XV siècles: problematique, financement, aspects sociaux», Fortifications, portes de villes, places publiques, dans le monde mediterraneen, bajo la dirección de HEERS, J. Paris, s.f., o el de IRANZO MUÑIO, M. - T.: La muralla de Huesca en la Edad Media, Huesca, 1988, donde analiza y reconstruye la misma y sus funciones a partir de las cuentas de los obreros de los muros entre 1444 y 1465 . Desgraciadamente no se ha conservado para Elche este tipo de documentación, que nos hubiera sido de enorme utilidad para nuestro trabajo. 


\section{El trazado de la muralla}

A través de los restos que han llegado hasta nosotros y de los planos de fines del siglo XVIII y de 1849 se ha reconstruido el perímetro de la muralla, cuyos orígenes se sitúan en época musulmana. Durante los años 1986 y 1987 el Museo Arqueológico Municipal de Elche realizó excavaciones en el solar emplazado junto a la «Casa de la Cova», por donde se supone que discurría la muralla medieval, que incidía sobre el Alcázar. Como señala A. Ramos, a quien seguimos, las prospecciones pusieron al descubierto una serie de habitaciones adosadas a la parte interna de los restos de muralla conservados, con abundante material cerámico, preferentemente de época almorávide y, sobre todo, almohade, reflejo de la tardía islamización de la zona ${ }^{9}$.

En 1989 R. Azuar, Margarita Borrego y Rosa Saranova realizaron excavaciones en la llamada «Casa de la Cort», junto al Ayuntamiento, habiéndose reconocido cuatro viviendas incompletas, de planta aproximadamente rectangular, con finalidad residencial, formadas por varias habitaciones alrededor de un patio y dos espacios funcionales bien definidos: las cocinas y los evacuatorios. Estas viviendas debieron construirse a finales del siglo XII. En esta zona la muralla tiene una orientación aproximada S-N, en paralelo al cauce del río, engarzada con el torreón de flanco que existió, o existe, dentro del edificio contiguo al Ayuntamiento. Su factura es de mampostería de gran tamaño trabada con mortero de cal, siendo su anchura de un metro en su parte superior. Según los citados arqueólogos había una calle, de carácter secundario, que discurría paralela a la muralla, posiblemente paralelo al gran eje de la muralla que vertebraba la trama urbana en esta zona de Elche. Este tramo de muralla de poniente debió levantarse a fines del siglo XII y la construcción del barrio residencial corresponde a la etapa de máximo desarrollo urbano de Elche, bajo dominio almohade, y se hizo siguiendo una trama ortogonal ${ }^{10}$.

Un hallazgo importante para conocer la muralla ilicitana se produjo el 15 de mayo de 1989 al cimentarse el solar que ocupó la Farmacia de Serrano, en Cuatro Esquinas, entre las calles Corredora y de la Victoria. Dado que se conocía el trazado de la muralla, no era raro que aparecieran estos restos, pero sí lo fue el comprobar que el lienzo se interrumpe en forma escuadrada para dejar un vano que corresponde a una puerta o portillo de acceso a la villa amurallada, en lo que hoy es calle de la Victoria. Supone replantear los estudios referentes a los accesos a la ciudad, tarea muy difícil de resolver en estos siglos por la escasez y parquedad de las fuentes, lo que hace de la Arqueología un complemento indispensable de la Historia.

Esta puerta se ha fechado en la segunda mitad del siglo XII. Está constituida por un reentrante en el lienzo exterior de la muralla de 2,50 metros, continuando por una cubierta abovedada, que cierra el vano. Adosado a este fragmento de muralla y perpendicular a él existe una obra hidráulica formada por un acueducto soportado por arcos de sillería, obra posiblemente de comienzos del siglo XVIII que permitía el discurrir del agua entre la vila murada y el exterior.

9 RAMOS FERNÁNDEZ, R. y PÉREZ MOLINA, T.: «Excavaciones arqueológicas en la muralla medieval de Elche», Pobladores de Elche, 10, 1988, pp. 41-59. AZÚAR RUIZ, R.; BORREGO, M.; SARANOVA, R.: Casa de la Cort (Elche). Campaña 1989, Memoria de excavaciones inédita. RAMOS FOLQUES, R.: Informe sobre los recientes descubrimientos medievales de Elche. Memoria inédita. Quiero agradecer aquí las facilidades prestadas por Alejandro Ramos en todo momento para la consulta de estos trabajos, así como también la de Rafael Navarro Mallebrera, director del Archivo Municipal de Elche, que tan amablemente puso los fondos documentales a nuestra disposición.

10 AZÚAR, R.; BORREGO, M.; SARANOVA, R.: Casa de la Cort (Elche). Campaña 1989. Memoria de excavaciones inédita. 
Así pues, sobre una cimentación musulmana se levanta la muralla medieval, que debió tener una altura de tres metros. Según el regidor Cristobal Sanz, en 1621, tenía un perímetro de 1.420 pasos y estaba dotada de foso y barbacana, 8 torreones grandes, 16 torres pequeñas y 8 torretas en la barbacana, sumando 32 torres ${ }^{11}$.

La muralla tiene un trazado rectangular, salvo el lado Sur, que es ligeramente oblícuo hacia el NE. En el lado Sur, como señala Gozálbez, la muralla iba desde el Vinalopó hasta la calle del Trinquete (Díaz de Mendoza), alineada con la fachada del actual Ayuntamiento. Las casas que sobresalen hasta la acera norte de la Corredora se edificaron adosadas a la muralla desde la segunda mitad del siglo XV. En el extremo Este, en el cambio de dirección hacia el Norte, se encontraba la torre de Vill, derribada en 1899. Desde aquí la muralla seguía en dirección Norte, pasando por la Calahorra, hasta el torreón de Get, situado al final de la calle del Facho (García Goldáraz), todavía en pie en 1870. El torreón servía de defensa a la muralla, que desde aquí «se desviaba hacia la puerta del cerco situada en la Casa-peña que existe hoy detrás del fuerte Torre-palacio...», según describía el cronista Torres en 1870, sin que sepamos a qué se refería al hablar de la Casa-peña, si bien Gozálvez supone que puede aludir a la torre principal de la Calahorra, que es cuadrada pero cuya parte inferior es más antigua que el resto del edificio, de mediados del siglo XVI.

Desde la esquina del palacio de Altamira la muralla torcía perpendicularmente hacia el Sur, siguiendo el cauce del Vinalopó hasta llegar a la altura de la actual fachada del Ayuntamiento ${ }^{12}$.

\section{Noticias históricas de la muralla}

Ya Al-Edrisi a mediados del siglo XII (1154) al referirse a Elche nos dice que la villa estaba amurallada y atravesada por un canal derivado del río ${ }^{13}$, descripción de tipo general que a fines del siglo XIII o principios del XIV repitió Al-Himyari.

Será tras la conquista cristiana cuando comencemos a tener noticias más precisas sobre los muros de Elche, en gran parte gracias a la preocupación de las autoridades municipales por una buena gestión de la administración municipal. La muralla es uno de los principales elementos de la vida urbana y será objeto de especial atención por parte de los señores y del Consell ilicitano. En 1284 doña Beatriz, viuda del infante don Manuel, destina anualmente 600 maravedís procedentes de las rentas de la tahurería para reparar las murallas ${ }^{14}$. Ésta parece ser entonces la principal fuente de financiación de la obra de los muros y así se mantuvo en el siglo XIV. Jaime II en 1320 concedió a las autoridades el producto de dos años de la tahurería para reparar las murallas, concesión ratificada por Alfonso IV en 1329.

A principios de siglo, el 18 de enero de 1307, incoporada Elche al reino de Valencia, Jaime II dispuso que se destinaran cada año 2.000 sueldos para reparar los muros, a los que la villa añadiría otros 1.000 más. El rey quiere facilitar la defensa de Elche, que la muralla esté en buen estado, y se muestra dispuesto a colaborar con parte de sus rentas en Elche, a la vez que deposita en el Consell local la responsabilidad del mantenimiento y la puesta a punto correcta del muro. Para los jurados la máxima preocupación era conseguir que el dinero llegara con regularidad, lo que no siempre sucedía.

11 SANZ, C.: Recopilación en que se da cuenta, p. 111. Lo reproduce GOZÁLBEZ, V.: La ciudad de Elche, pp. 27-28.

12 GOZÁlVEZ, V.: La ciudad de Elche, pp. 28-29.

13 AL-EDRESI: Descripción de España, en GARCÍA MERCADAL, J.: Viajes de extranjero por España y Portugal, Madrid, 1952, 1, pp. 183-212. GOZÁLVEZ, V.: La ciudad de Elche, p. 24.

14 IBARRA, P.: Historia de Elche, Alicante, 1895. RAMOS, A.: Historia de Elche, ob. cit. p. 106. 
Los años centrales del siglo XIV, 1348-1375, fueron de gran conmoción política y militar en el reino de Valencia, debido a la guerra de la Unión (1348-1349) y a la guerra contra Castilla entre 1356-1375, que en la gobernación de Orihuela tuvo uno de sus principales escenarios bélicos en tierras valencianas. Estos años generaron una intensa actividad constructiva y de puesta a punto de nuestras fortificaciones. En Elche las autoridades se preocuparían por mantener las murallas en buen estado, pero la carencia de actas municipales hasta 1370 impide precisiones al respecto. Para esta fecha el peligro castellano se había disipado y se suprimieron las rondas en las murallas, mientras que el 15 de marzo, la reina Leonor, tutora del infante Martín, reglamentó la contribución de los moros ilicitanos con dos hombres a la reparación de los muros y valladares de la villa ${ }^{15}$. El 2 de julio de 1378 el infante don Martín autorizaba a Elche a imponer sisas sobre el pan, vino y otros artículos con el fin de reparar los muros y valladares por un período de 12 años.

No debía ser malo el estado de conservación de las fortificaciones de Elche a fines del siglo XIV, por cuanto sólo hay noticias de dos obras en los muros en 1382 y 1384 , pretextando el peligro de «guerra de moros», que era el recurso habitualmente utilizado por las autoridades para movilizar a los vecinos en esta tarea colectiva tan poco atractiva.

En el siglo XV son frecuentes las noticias sobre las murallas, y a ellas nos referiremos más adelante. La función defensiva sigue siendo prioritaria, la principal razón para mantener en buen estado la muralla, aunque en este siglo la tensión bélica experimentó un notable descenso, a pesar de que siguieron las correrías de los jinetes nazaríes. El peligro real vino de los castellanos, como consecuencia de la guerra entre Aragón y Castilla en 1429-1430. El 26 de agosto se produjo un ataque castellano a Elche, a los arrabales, trabándose combate. El enemigo cometió todo tipo de excesos, incluyendo la quema del pueblo. El gobernador, ante tales noticias, escribe el 8 de septiembre a los jurados y les pide que adopten medidas de protección ordenando desalojar el arrabal y la morería, debiendo refugiarse todos tras la muralla, so pena de 10.000 florines $^{16}$.

También en la segunda mitad de la centuria hubo un momento de peligro con motivo de la rebelión catalana, en que se adoptaron medidas de seguridad y de refuerzo en las murallas. En 1462 el Consell ordenó que se nombrara una junta de defensa para atender lo que fuera necesario en el muro, construyéndose barreras en el arrabal cristiano de la Pobla de Sant Jordi y junto al burdel. Pero el peligro era más hipotético que real, aunque fue una buena ocasión para poner a punto la muralla.

\section{Los componentes de la fortificación de la villa}

La muralla disponía de una serie de puertas que ponían en comunicación el interior de la villa con el territorio circundante. La puerta tenía una gran importancia, ya que «era la expresión de la voluntad de la ciudad, de su actitud respecto a una gran cantidad de problemas y de gentes» ${ }^{17}$.

Las puertas podían ser atravesadas sin problemas en primer lugar por los vecinos de la villa y también por los forasteros, pero también podían ser el camino de salida hacia el exilio, hacia el destierro cuando las tensiones sociales, las luchas de bandos oponían a los distintos grupos sociales, luchas que a menudo se saldaban con el destierro de los vencidos.

15 IBARRA, P.: Historia de Elche, ob. cit., p. 50.

16 RAMOS, R.: Historia de Elche, ob. cit., p. 118.

17 GUGI TELMI, Nilda: «Muros y puertas en el paisaje urbano. (Italia del centro y del norte. Siglos XIIIXV), Acta historica et archeologica Medievalia, 9, 1988, p. 333. 
Otras veces la expulsión era resultado de la pena impuesta por las autoridades a los transgresores de la ley, con el fin de evitar venganzas privadas por el grupo perjudicado.

Había también grupos de la comunidad que por razones religiosas eran rechazados o discriminados ante las puertas. En Elche tenemos un claro ejemplo con los moros de la villa, asentados en el arrabal, y considerados en la práctica como vecinos de segunda clase. El 30 de septiembre de 1400 los jurados deciden arreglar las murallas, y entre las razones aducidas figura el que los moros no entren de noche en la villa a hora no legal por las partes derruidas. Se ordenó al portero encargado de la puerta que desde que sonara la señal hasta el alba no dejara entrar a los moros en la villa, y sólo podrían hacerlo uno o dos acompañados por un vecino cristiano con el fin de hacer sus negocios ${ }^{18}$.

El tema de las puertas ha pasado prácticamente desapercibido para los estudiosos de Elche. El cronista Torres habla en 1870 de una «puerta del cerco», que V. Gozálbez sitúa al Sur, frente a la torre principal, cuadrada, del Alcázar, con salida hacia la Rambla, dado que «la plazoleta ante la fachada de este edificio tiene las mismas características que las existentes frente y a intramuros de las otras dos puertas de la muralla, las plazas de la Fruta y de Santa Isabel» ${ }^{19}$. Esta puerta sería secundaria frente a las dos puertas principales de la villa, llamadas por Gozálvez de la vila o Calahorra y la del Consejo o Guardamar, aunque debiera titularse de Orihuela. Aquí hay una confusión, y la puerta de la vila no es la de la Calahorra, sino la que denomina del Concejo. Hay un texto de 1420 , que reproduce Gozálvez, en el que ante el peligro de correrías de los moros granadinos se ordena el cierre nocturno de todas las puertas de la villa, «ço es la porta de la Calaforra tro al sol eixit, $e$ la porta de la vila approp la plaça tro al jorn clar..», entregándose las llaves de la puerta de la villa a una de las rondas, cerrándose con la cadena ${ }^{20}$. Quizá pudiera producirse a principios del siglo XV un cambio en la nomenclatura y la Porta de la Vila-Porta de la Calahorra fue la principal hasta entonces, hasta que se produjo un desplazamiento del centro político de la localidad al área donde luego encontramos la Porta de la Vila. Pero ello no es más que una mera hipótesis. La puerta de la vila se abría entonces a la plaza Mayor (Plaça de la Fruita) y adquirió mayor importancia a raíz de la edificación de la torre del Consell en 1441. La documentación al referirse al espacio abierto frente a la Porta de la Vila indica siempre la plaça por antonomasia. En un documento del 14 de febrero de 1429 se especifica de forma clara «l. . porta dels murs appellada de la plaça o mercat». Esta puerta fue reparada en 1439 por el albañil y carpintero Antoni Soriano y Acarpi, moro herrero.

Ambas puertas se localizaban en posición diagonal respecto al recinto amurallado, en relación a los dos ejes de circulación principales: los caminos de Alicante y Orihuela, y sus repercusiones urbanísticas se aprecian en que la puerta de la Calahorra ofrece una concentración radial que desemboca en la plazuela de Santa Isabel, mientras que la de la Vila genera unas manzanas menos rectangulares ${ }^{21}$.

Hasta aquí lo que sabíamos sobre las dos puertas y un portillo en el muro de Elche. Pero las fuentes añaden nuevos datos. Así el 25 de agosto de 1443 los jurados acuerdan que el portal que hay roto, cerca de la casa de Jaume Costa, sea reparado y se construya un portal mediano, con puertas ${ }^{22}$. El problema estriba en saber dónde estaba la casa de Costa, tarea imposible de momento.

\footnotetext{
18 ARCHIVO MUNICIPAL DE ELCHE (A.M.E): Manual de Consells, 2, fol. 58 r-v.

19 GOZÁlVEZ, V.: La ciudad de Elche, ob. cit., pp. 28-29.

20 GOZÁl VEZ, V.: La ciudad de Elche, ob. cit., p. 29. A.M.E. Manual de Consells, 4. 1-9-1420.

21 GOZÁlVEZ, V.: La ciudad de Elche, ob. cit., p. 31.

22 A.M.E.: Manual de Consells, 12, fol. 280 r.
} 
El 14 de julio de 1444 se encargaron a Joan de Feyna, de Alicante, la confección de unas puertas nuevas con madera de Valencia, para el Portal Nou de la villa, que estaba junto a la lonja, costando 35 libras $^{23}$. Pedro Ibarra señaló que la villa tenía dos puertas, la de la villa, el camino de Alicante, defendida por la Calahorra, y la de la Lonja, que correspondería a la que Gozálvez llama del Concejo, que no es otra, como antes he indicado que la Porta de la Vila. Se situaba en la plaza y en 1436 los jurados se refieren a la torre del Consell que se ha ordenado hacer encima del portal de la Vila ${ }^{24}$. En 1441 en un acuerdo del Consell sobre dicha torre, un copista añadió la frase «Torre sobre la Lloja», con lo que la Porta de la Vila y la de la Lonja son una misma.

El problema está en identificar el mencionado Portal Nou. Su situación junto a la Lonja podría inducir que se trataba de la puerta de la Vila, pero no hay razones que permitan suponer un cambio repentino de nombre, máxime cuando años después sigue apareciendo el Portal de la Vila en los textos. El nombre que se le da: «Portal Nou» puede aportar alguna pista. Por un lado, cuando la documentación se refiere a las puertas que llamaríamos principales utiliza siempre la forma «porta», dejando la denominación de portal para puertas de menor tamaño, como la realizada en 1443. Por otro lado, el hecho de que se le califique de $\mathrm{Nou}$ alude sin dudas a una edificación nueva, reciente, posiblemente la que se acordó abrir en agosto de 1443. El principal problema es ubicarlo, dada la ambigüedad de la frase «junto a la lonja», o cerca de la casa de Jaume Costa, ya que la no coincidencia de ambos datos es un obstáculo para la identificación propuesta de ambos portales. La cronología, julio de 1443 a agosto de 1444, nos inclina a pensar en un mismo portal.

El recinto amurallado tenía también una serie de portillos, en número no determinado, de los que nos han llegado noticias por obras realizadas en ellos, como la de octubre de 1400 para reparar un portillo derribado. En 1414 hubo obras en otro portillo situado cerca del molino del Alcázar. Otro estaba situado junto a la casa de Joan Guillo y en febrero de 1449 se hicieron para él unas puertas de madera ${ }^{25}$.

Las puertas eran también un instrumento de control en manos de las autoridades, que seleccionan a los transeuntes. Los jurados nombran al portero que se encargará de abrir y cerrar dichas puertas, siendo el justicia el que tiene las competencias para determinar su apertura o cierre. El nombramiento de porter lo efectuaba el Consell y no tenía una duración establecida, sino que quedaba al arbitrio de las autoridades, que podían revocar al sudodicho empleado si no cumplía correctamente su función.

El muro estaba rodeado de un foso o vayl, del que sólo ha llegado alguna que otra noticia dispersa. En 1384, ante una amenaza granadina, los jurados deciden cerrar el foso por delante del molino del Alcázar y la fábrica de curtidos de Jaén, llenándolo de agua. Los vecinos colaborarían en lo que fuera necesario y llevando piedras ${ }^{26}$.

Si se quería mantener en buen estado los muros era imprescindible que las canalizaciones de agua estuvieran limpias, sin obstrucciones, que dañaban la construcción. En 14-81400 se encargó a Francesc Català, maestro albañil, que cuidara, reparara y pusiera a punto los canales y albellones de los muros y la barbacana ${ }^{27}$.

De la barbacana hay pocas noticias, como el acuerdo del Consell de 22-11-1401 de que sea limpiada y aplanada, así como sus albellones. En 1379 la barbacana se utilizaba como lugar de juego, aunque ilegalmente, costumbre que ha perdurado hasta tiempos recientes en muchas localidades valencianas.

23 A.M.E.: Manual de Consells, 12, 14-7-1444.

24 A.M.E.: Manual de Consells, 9, 18-4-1436.

25 A.M.E.: Manual de Consells, 12, 19-2-1449.

26 RAMOS, R.: Historia de Elche, ob. cit., p. 119.

27 A.M.E.: Manual de Consells, 11, 14-7-1444. 
Elemento de gran trascendencia en la muralla eran las torres y torreones. Cristóbal Sanz, en 1621, habla de ocho torreones grandes «que ciñen y abrazan la barbacana», para los que Gozálvez propone la siguiente identificación: torre del Consejo, sobre la puerta de Guardamar o Lonja - es decir, de la Vila_; la segunda sería la torre de la Vela o de Calendura, donde se emplaza el reloj de este nombre; la tercera corresponde con la de Vill o de Don Joaxim, nombre de su propietario, Joaquín Perpiñán; la torre principal era la de la Calahorra, en la cual se produjo la entrega de Elche a Jaime I en 1265; la quinta torre, la de Get, defendía el ángulo nordeste de la muralla, mientras que la del Alcázar, la sexta, se situaba en el extremo noroeste. La séptima y la octava correspondían a las torres de Cotí, que defendía el lado del río, y la designada con el nombre de Oco, situada en el ángulo suroeste de la muralla, como se ve en un plano de 1849. En 1621 la muralla contaba con 16 torres pequeñas. Entre éstas figuraría la que aparece en el escudo de la ciudad, que según Ramos Folqués, correspondería a la situada frente a la Calahorra, enmarcando la Porta de la Vila ${ }^{28}$.

Nos encontramos con una descripción del siglo XVII, que no sabemos hasta qué punto se puede considerar válida para doscientos años antes. Por de pronto, los topónimos son diferentes, ya que salvo la torre del Consell y la de la Calahorra, ninguno de los otros nombres aparece en la Edad Media. En el siglo XV sólo se mencionan por sus propios nombres dos torres: la del Consell y la de la Campana. Ninguna fuente indica el número de torres existentes a fines de la Edad Media, ignorando de las ocho de 1621 cuántas son medievales y cuántas posteriores.

Hay, por tanto, pocas noticias sobre las torres de la muralla. Sabemos que en 1370 el Consell ordenó limpiar la acequia porque había caído encima un torreón. La torre de la Campana aparece mencionada en 1437, año en que los jurados acuerdan traer una campana que había en la Calahorra y que pertenecía a la iglesia de Sant Jaume, con el fin de colocarla encima de dicha torre. La finalidad era que el obrero del muro pudiera avisar a toque de campana a los que debían acudir a la obra del muro. Fue aquí donde se instaló el primer reloj público de Elche, y el 6 de abril de 1439 se pagaron 195 sueldos a Bertomeu Yidal, cantero, por construir los campaniles de la torre de la Campana, donde se pondría el reloj $^{29}$. Ignoramos la relación entre esta torre y la de Calendura, ya que el reloj nuevo no se hizo hasta 1571, aunque cabe suponer que no estaría muy lejos del anterior emplazamiento, si no era el mismo.

La torre del Consell tenía sus obras ya en marcha en 1441 y el 14 de agosto el Consell acordó que se terminara hasta la primera cubierta, encargándose de la obra mestre Briant y sus compañeros por 3.500 sueldos. El plazo de las obras era hasta el 1 de abril de 1442 y el maestro se ceñiría al proyecto que le había entregado el Consell. La bóveda de la cubierta y los arcos serían de piedra. El maestro Briant y sus compañeros residían en Orihuela y es un buen ejemplo de una logia de cantero y albañiles que ofrecen sus servicios allí donde son requeridos. La fama de Briant y la ausencia en Elche de buenos especialistas para trabajar la piedra le granjearon la confianza del consistorio ilicitano y en 1442 seguía trabajando en las obras.

Aunque el muro era el elemento defensivo más importante para la villa no era el único, y como complemento del mismo existían la Calahorra y el Alcázar. No vamos a entrar en una descripción pormenorizada de los mismos. Simplemente recordar que el Alcázar de la Señoría o palacio de Altamira se levanta en la plaza del Palacio, frente al Vinalopó, y ha sufrido numerosas transformaciones desde sus orígenes en época almohade, posiblemente

28 GOZÁLVEZ, V.: La ciudad de Elche, ob. cit., pp. 29-30. RAMOS, A.: Historia de Elche, ob. cit., p. 441. 29 A.M.E.: Manual de Consells, 12, 11-4-1439. 
a fines del siglo XII o principios del XIII. La torre del homenaje, cuadrada, es posible que formara parte, como sugirió Ibarra, del recinto amurallado musulmán. El resto del edificio es de fines del siglo XV y principios del XVI a impulso de los Cárdenas, señores de Elche.

La torre de la Calahorra o Calaforra, singularizada siempre en la documentación medieval dada su relevancia es, en opinión de R. Azúar, un edificio musulmán de finales del siglo XII o principios del XIII, situada frente a la plaza de la Merced, por donde antaño salía el camino hacia Alicante. Debió tener una altura de 26 metros, de los que sólo quedan 15 , a causa del terremoto de 1829. Tiene cuatro cuerpos, troneras y matacanes, siendo la base rectangular y los muros inclinados en talud ${ }^{30}$.

A principios del siglo XV el estado de ambas edificaciones era bastante deficiente y el 29-10-1401 el Consell se quejaba porque ambos edificios y la prisión se estaban cayendo, debido a que la señoría (Barcelona) no efectuaba las reparaciones necesarias, por lo que se hicieron gestiones con las autoridades barcelonesas para que proveyeran los fondos necesarios a dichas obras. El carácter emblemático de estos edificios, símbolo del poder señorial, impide que el Consell tome decisiones en cuanto a su mantenimiento, ya que no son de su propiedad, sino del señor, en estos momentos la ciudad de Barcelona. Pero la capital catalana está lejos y lo único que le interesa de Elche es la renta que de la villa puede obtener, lo que hace difícil mantener ambos edificios.

\section{Política económica del Consell en los muros}

La construcción y mantenimiento de las murallas era una tarea colectiva, dirigida por el Consell, que destinaba una serie de inversiones para las obras de fortificación. En el caso de Elche no podemos efectuar un estudio minucioso de tipo financiero sobre las murallas, debido a la ausencia de libros de clavería o de cuentas. Ignoramos lo que representaba el gasto de los muros con respecto a otros capítulos del municipio. Por lo general las cantidades asignadas a los muros suelen tener un carácter extraordinario, aprobadas en los momentos de necesidad, aunque teóricamente existían unas cantidades fijas concedidas por la Corona o la señoría, pero que no sabemos si se mantenían o se destinaban a otros usos.

Reparaciones de las murallas de Elche las hubo con bastante frecuencia en estos siglos bajomedievales. Por lo general se acude al procedimiento de reparaciones urgentes cuando se produce la inminencia de un peligro militar o bien cuando el mal estado de la defensa ha alcanzado un fuerte grado de deterioro, lo que hace imprescindible su reparación por razones de seguridad, de higiene para el vecindario, etc.

Uno de los motivos que se aduce con más frecuencia para llevar a cabo tales reparaciones es el peligro de «guerra de moros» granadinos. Son noticias que llegan a oídos de los jurados a través de almogávares, viajeros, espías de las autoridades murcianas, que avisan de las supuestas intenciones de los granadinos de atacar el territorio valenciano. La mayoría de las veces las alarmas eran falsas, pero los ataques de los corsarios al puerto del Cap del Aljup o las entradas de almogávares y el cautiverio de vecinos de Elche mostraban que no se trataba de un temor infundado. De ahí que, unas veces justificadamente y otras con la excusa del ataque de los moros, las autoridades se aprovecharan de ello para hacer que los vecinos, cristianos, moros y judíos cooperaran en reparar los muros.

El mal estado de conservación del cinturón defensivo era un mal endémico en la mayoría de las localidades valencianas de la época, y Elche no fue la excepción. El 30 de

30 AZÚAR, R.: Catálogo de monumentos y conjuntos de la Comunidad Valenciana, Valencia, 1983. I. pp. $420-423$. 
septiembre de 1400 los jurados reconocían que la Porta de la Vila por la noche estaba casi abierta y los muros estaban en algunos lugares derruidos, mal dispuestos, con gran peligro para la villa «que es quasi a manera de castell e poblada e edificada entre moros». Se dispuso su reparación, pagando los moros su parte alicuota ${ }^{31}$.

En años sucesivos hubo diversas reparaciones del muro, como en 1420, 1421, 1427, siendo preocupación constante de los jurados el que las obras se hicieran con rapidez y calidad. El 15 de julio de 1430 se acordó abrir un trozo de muro encima del molino de la villa, paralizándose los trabajos en octubre a causa de la lluvia y de la siembra. En 1434 las reparaciones afectaron al trozo de muro que había frente a las casas de Pere y Joan Quexans, destacados miembros del patriciado local, que continuaban en 1435. El 25 de julio se encargó al obrero del muro la construcción de unas barreras en el arrabal, en aquellos puntos que las autoridades creyeran oportuno. En 1450 hubo que rehacer el muro que se había levantado junto a la casa de Llorens Garbeller, sastre, y la de Joan Quexans, notario $^{32}$. Hay otros muchos más ejemplos de parcheado, de refuerzo temporal de las partes ruinosas, con el fin de que la muralla pudiera seguir desempeñando su función defensiva y de control.

\section{El financiamiento y mantenimiento de la muralla}

El mantenimiento de la muralla era una obligación de los habitantes de la villa o ciudad, y también por lo general de sus aldeas. Ya vimos cómo la Corona o los señores láicos de Elche destinaron ciertas cantidades para el sostén y reparación de los muros, procedentes de las rentas de la tahurería. El 5-12-1415 el Consell acordó perdonar a los jugadores de cartas y dados que habían sido condenados a la pena de 60 sueldos, destinando el tercio correspondiente al Consell para la reparación de la muralla ${ }^{33}$.

La contribución más importante fueron los 2.000 sueldos que Jaime II dispuso que se destinaran anualmente para dicho mantenimiento, más otros 1.000 que pondría el Consell, aunque ignoramos si se cumplió tal propósito, ya que con frecuencia vemos a las autoridades recurriendo a otra fuente de financiación, como en 1371 con el producto de las multas a los ganados que entraran ilegalmente en el bovalar de Elche. El 30-8-1401 se cuerda destinar mil sueldos anuales a reparar los muros, procedentes del arrendamiento de la sisa, lo que supondría la puesta en vigor de aquella obligación de $1307^{34}$. En algún caso eran fondos procedentes de una concesión extraordinaria, como la hecha por la ciudad de Barcelona el 2 de enero de 1401 al Consell de los bienes que fueron de la sinagoga local, destinado el producto de su venta para las murallas.

La administración de las murallas de Elche era competencia del Consell, que nombraba entre los vecinos a un obrer dels murs. El cargo era anual, designado en una de las sesiones ordinarias posteriores a la elección de los jurados y restantes oficios municipales, que tenía lugar tres días antes de la Pascua de Quincuagésima. Solía ser en los meses de mayo y junio, aunque con efectos retroactivos desde Pascua. En ocasiones el obrero podía renunciar al cargo, nombrando los jurados a otra persona en su lugar. Otras veces la sustitución podía deberse al fallecimiento de la persona que desempeñaba el cargo.

Una novedad importante en el sistema de nombramiento del obrero se produjo el 26 de

31 A.M.E.: Manual de Consells, 2, 30-9-1400.

32 A.M.E.: Manual de Consells, 14, 1-8-1450.

33 A.M.E.: Manual de Consells, 3, 5-12-1415.

34 A.M.E.: Manual de Consells, 2, 30-8-1401. 
mayo de 1443. En la reunión del Consell de ese día se acordó que el futuro obrero de los muros sería elegido el tercer día de Pascua de Quincuagésima de acuerdo con el siguiente procedimiento: que de aquellos tres nombres de hombres buenos que se metían en el bacín para elegir el clavario, el primero de los redolinos que se extrajeran correspondería al clavario, y de las otras dos bolitas que quedaran en el bacín, un niño sacaría una, que sería el obrero de los muros. La ordenanza duraría a beneplácito del Consell ${ }^{35}$. Estos cambios posiblemente estuvieran en relación con las modificaciones introducidas en el sistema electoral del municipio de Elche, tema de futuro estudio.

Lo cierto es que del nombramiento directo se pasa aun sistema en el que la suerte juega un papel hasta cierto punto determinante, dentro del escaso margen de «democracia» que permite el sistema, ya que los candidatos son elegidos por las propias autoridades, pero al menos ya existe una triple posibilidad. Lo que no excluía las tensiones en el seno de la oligarquía local, como se ve en mayo de 1487, cuando el justicia y los jurados no se ponen de acuerdo sobre quién debería ser el obrero de los muros.

Viendo las listas de los obreros de muros que conocemos, a través de sus apellidos se aprecia que muchos de ellos pertenecían a un reducido grupo de la oligarquía urbana, lo que se ha llamado el patriciado local. Son los Ferri, Malla, Santa Cilia, etc. que controlan los puestos políticos y económicos del municipio, igual que en otras localidades vecinas como Alicante u Orihuela. A través del sistema de cooptación la clase dominante controla los destinos del municipio. Y el puesto de obrero de los muros es apetecible porque se maneja bastante dinero y se está en estrecho contacto con los intereses constructivos del municipio, que pueden ser utilizados en beneficio de los objetivos económicos de esta oligarquía. El título de honrat que llevan algunos de los aspirantes refleja su destacado puesto en la escala social local, mientras que una ordenanza del 25-5-1448 estipula que ningún vecino que fuera deudor o fiador del Consell podría ser obrero de los muros ni de la torre del puerto o de las obras de la acequia ${ }^{36}$.

El Consell mantiene el control de las funciones del obrero, ya que cualquier obra que éste emprenda deberá ser con el acuerdo previo del justicia y jurados de la villa, así como de algunos prohombres. Su salario es el siguiente: cada día que trabaje con dos peones cobraría dos sueldos; el día que vaya con cal o yeso otros dos sueldos; cuando arranque piedra y la tire, cal o arena para la obra con 4 o más peones cobraría dos sueldos. Si el trabajo es de sólo medio día cobra un sueldo. Estos salarios se mantuvieron fijos todo el siglo XV.

El obrero del muro se encargaba también de otras tareas que podríamos calificar como de policía y urbanismo, como por ejemplo la retirada de piedras de las calles, o de la venta pública de la cal. Era responsable de los capitales manejados y debía rendir cuenta de su gestión anual a una comisión nombrada por el Consell, anotándose los gastos en los libros de cuentas, cuya ausencia nos impide conocer el uso de los recursos de la villa por la clase social dominante. Para todos los gastos superiores a cinco sueldos el obrero del muro debía presentar la correspondiente factura ante los auditores, pudiendo no hacerlo si la cantidad era inferior, bastando entonces el juramento del obrero.

Otra de las obligaciones del obrero del muro era la elaboración de un inventario con los utensilios disponibles para las obras de la muralla, debiendo entregarlo al sucesor, que lo comprobaría antes de su aceptación. Su confección fue muy irregular y sólo hemos encontrado dos o tres de ellos, que nos muestran unos utensilios habituales en este tipo de

35 A.M.E.: Manual de Consells, 12, 26-5-1443.

36 A.M.E.: Manual de Consells, 13, 25-5-1448. 
labores: martillos, capazos y el habitual instrumental de albañilería, a menudo en deficiente estado de conservación.

En torno a las murallas giran también otros personajes secundarios pero imprescindibles para que éstas puedan llevarse a cabo, ya que el obrero del muro no es más que el administrador por cuenta del Consell. Me refiero, por ejemplo, al maestro de obras contratado por los jurados cuando su presencia se considera necesaria, como se hizo en 1420 con Mateu Sunyer como maestro de la obra del muro.

La mano de obra para construir o reparar las fortificaciones en Elche eran los peones cristianos, moros o judíos sujetos a tal obligación. Al frente se encuentra un capataz, designado por el Consell, por el plazo que crea oportuno. En los años treinta del siglo XV hay una mejor regulación del cargo, que pasa a tener una duración anual, entre las dos Pascuas de Quincuagésima. Una vez nombrado recibe el libro de los peones cristianos de la villa, que debían acudir a las reparaciones según su tanda. Como salario percibía en 1402 el de un peón por cada doce, suma que se mantuvo en años sucesivos, mientras que en 1427 hubo un aumento, a pasar a cobrar el de un peón por cada diez que fueran, cantidad que en 1439 se rebaja, siendo el de un peón por cada veinte.

El mantenimiento y construcción de la muralla obligaba a todos los vecinos de Elche, aunque no conocemos bien los orígenes y el mecanismo por el que se regía dicha contribución, similar al de tantas otras poblaciones. Su origen se remontaría a los años posteriores a la conquista, cuando se va consolidando el dominio cristiano y la inseguridad de la época (revuelta mudéjar de 1264), impone la necesidad de un recinto defensivo en buenas condiciones. En esta obligación común participaban los tres colectivos de la villa: cristianos, moros y judíos - estos últimos hasta 1391 en que se extinguió la judería-, de acuerdo con un sistema de turno o tanda. Los moros dependían para todo ello del baile local.

El 29 de octubre de 1402 el Consell introduce una importante novedad en el reclutamiento de los peones ordenando que todo vecino que tuviera bienes de realengo en la villa o su término entregue como pecha vecinal un peón para la obra de los muros por cada tanda a la que sea convocado. Si no tiene bienes de realengo que pague por cada casa un peón por tanda. La condición de vecino era indispensable para ser incluido en esta carga colectiva de construcción y mantenimiento del muro, y a la vez una garantía contra posibles abusos en otras localidades.

A veces las autoridades eximían de acudir a trabajar en dichas obras a determinados individuos en razón de su pobreza o por circunstancias especiales. En 1424 la mujer de Ginés Xerta es declarada franca del peón del muro por ser pobres y estar su marido fuera ${ }^{37}$. Los buenos servicios prestados a la villa le valieron a mestre Aduart el ser eximido de estos trabajos en los muros. En ocasiones los peones del muro podían ser destinados por los jurados a realizar trabajos de utilidad pública, y así en 1453 se destinaron 4 peones para limpiar el pozo de la Vall Longa, utilizado por la villa ${ }^{38}$.

Por las obras realizadas en la torre de la Campana sabemos que esta campana era la que servía para avisar a los peones que debían acudir a las obras del muro. El que no acudiera a dicho toque debía contratar por su cuenta a otro hombre que fuera en su lugar, y de no acudir se le confiscarían bienes, siempre que fuera mayor de 15 años, lo que nos está indicando la edad a partir de la cual se era apto para participar en trabajos municipales. El Consell fijaba la hora de convocatoria de los peones, que desde octubre de 1410 quedó

37 A.M:E.: Manual de Consells, 5, 3-9-1424.

38 A.M.E.: Manual de Consells, 14, 18-11-1453.

39 A.M.E.: Manual de Consells, 2, 13-10-1401. 
fijada antes de que tocaran a misa, y pasado dicho toque si el peón acudía a la obra no sería admitido, debiendo alquilar otro peón a su costa. En 1435 la hora acordada era la del toque de ánimas, manteniéndose las mismas medidas para contener el absentismo, cuyo índice ignoramos.

Sobre los materiales utilizados en las obras no podemos seguir una evolución detallada de los mismos al faltar los libros de obras, pero los más utilizados eran la piedra, procedente de las canteras municipales, de cuya extracción, corte y traslado se encargaba el obrero del muro. Los otros dos materiales mencionados son el yeso y la cal, más difíciles de obtener, generalmente por vía de compra fuera del municipio. Las autoridades locales y de la gobernación controlaron mucho los hornos de yeso y de cal para evitar la deforestación del territorio, que ya por entonces debía estar bastante esquilmado, puesto que de Elche debían acudir a Aspe a por leña.

\section{Algunos aspectos sociales de la muralla de Elche}

La muralla tenía una significación social y económica que sobrepasaba el sentido preferentemente defensivo de la misma. Son aspectos de la vida cotidiana en torno a los cuales se tejía la vida del hombre de la época.

Ya hemos visto como los muros tenían un fuerte componente social, por cuanto están al servicio de la comunidad de vecinos y es el cuerpo social el que debe velar por su conservación. Pero en torno a la muralla giran toda una serie de actitudes y gestos muy variados, desde arrojar las basuras o los materiales de desecho en el foso, casi siempre cegado, al juego en sus alrededores o como soporte de la campana que convoca a los vecinos y más tarde del reloj.

El mercado y la feria se situaban en la Plaça Major, cerca de la Porta de la Vila, el único espacio notable abierto en el entramado viario del Elche medieval, mientras que las puertas servían de control para la entrada y salida de mercancías, para el cobro de los peajes.

El muro de Elche no estaba exento, sino que a él se adosaban numerosas viviendas y una ordenanza municipal del 22 de febrero de 1429 disponía que quien tuviera casa contigua o enfrentada con los muros de la villa y quisiera repararla, debería ser visitada primero por los jurados y varios prohombres para reconocerla, entregándoseles a continuación mortero y argamasa para obrar ${ }^{40}$. La intromisión de los particulares en el muro llegó al extremo de abrirse ventanas en el mismo, tras obtener permiso del Consell.

La muralla, con sus amplias superficies, era también lugar favorito de los juegos de los niños y jóvenes, con el consiguiente deterioro, por lo que el 22 de noviembre de 1450 los jurados prohibieron que en los muros y las barbacanas se jugara a pelota y otros juegos a los que allí se jugaba habitualmente, bajo pena de 20 sueldos. Una problemática, en definitiva, similar a la de cualquier localidad mediana del reino de Valencia a finales de la Edad Media. 